\title{
Growth of the uterus
}

\author{
N A Bridges, A Cooke, M J R Healy, P C Hindmarsh, C G D Brook
}

\begin{abstract}
Background-The pattern of growth of the uterus was examined by ultrasound examinations of 358 girls who attended a paediatric endocrine outpatient department but were shown not to have any endocrine defect.

Method-The uterus was measured in length and width at the cervix and at the fundus (cm). Endometrial thickness was measured (mm). Scans were divided by Tanner breast stage and the dimensions compared by one way analysis of variance (ANOVA, with the Student Newman Keuls post hoc test).

Results-There was an increase in uterine length, diameter of the fundus, and endometrial thickness at each breast stage from 1 to 5 (ANOVA, p<0.05), and in the diameter of the cervix with each breast stage from 1 to 4 (ANOVA, p<0.05). The ratio of the fundus to the cervix increased from 0.95 to 1.29 between breast stages 1 and 4.

Conclusion-The onset of puberty is marked by an increase in the dimensions of the uterus and in endometrial thickness, but also by a change in the shape of the uterus from a tubular to a pear shaped organ.

(Arch Dis Child 1996;75:330-331)
\end{abstract}

Keywords: uterus, endometrium, ultrasound.

Ultrasound is painless and non-invasive, and even in infants can determine the dimensions of the uterus and ovaries. Endometrial and myometrial cells are oestrogen responsive ${ }^{12}$ and the uterus increases in size during puberty. Information on uterine size and shape and on the thickness of the endometrium are useful in the assessment of girls with sexual precocity and pubertal delay. Published data on the pattern of growth in normal individuals are limited. ${ }^{3-5}$ We have examined the dimensions of the uterus in a large group of girls with no endocrine defect.

London Centre for Paediatric

Endocrinology and

Metabolism, Middlesex

Hospital, Mortimer

Street, London W1N

8AA

NA Bridges

A Cooke

MJR Healy

PC Hindmarsh

CGD Brook

Correspondence to:

Professor Brook.

Accepted 6 June 1996 formed. A full bladder was required to image the pelvic organs. At each scan, the uterus was measured in three dimensions (in $\mathrm{cm}$ ): length (from top of the fundus to the cervix), diameter at the fundus, and diameter at the cervix. The cervical diameter was not routinely measured when the uterus was an adult size. The thickness of the endometrium was measured (in $\mathrm{mm}$ ). Puberty was staged by the method of Tanner, ${ }^{6}$ and menarche was recorded.

REPRODUCIBILITY OF ULTRASOUND

MEASUREMENTS

To determine the reproducibility of linear measurements made at ultrasound, six ultrasound examinations were performed in duplicate. Examinations were performed by two experienced ultrasonographers on six individuals at the same occasion, with the second examiner 'blind' to the results of the first examination. The coefficient of variation (CV) ranged from 0 to $32.0 \%$. Plotting the difference between pairs against the mean of the pairs (the Bland-Altman plot ${ }^{7}$ ) demonstrated a trend for greater errors in the larger measurements (equation of line: difference $=0.08$ (mean) -0.07; correlation coefficient $=+0.57$ ).

\section{ANALYSIS OF DATA}

The scans from the patients were divided by Tanner breast stage. Mean values for the measurements made at each pubertal stage were calculated and compared by one way analysis of variance (ANOVA, with the Student Newman Keuls post hoc test). The ratio of the diameter at the fundus and the cervix was calculated for each scan, and a mean ratio calculated for each pubertal stage. The length measurements for the scans at breast stage 1 were plotted against age and a regression line calculated.

\section{Results}

Table 1 shows the numbers in each group, the ratio of fundus to cervix and the endometrial thickness, divided by pubertal stage. Figure 1 shows the uterine dimensions (SE) according to Tanner breast stage. ANOVA demonstrated an increment in uterine length, fundus diameter, and endometrial thickness at each breast stage from 1 to $5(p<0.05)$, and in the diameter of the cervix with each breast stage from 1 to 4 (ANOVA, p <0.05). Figure 2 shows the measurements of uterine length at breast stage 1 plotted against age. The equation of the best fit line was length $=0.093$ (age) $+2.67 ; r=0.50$. This line cannot be extrapolated to 0 years, because numbers at this age are insufficient. The uterus is probably larger in the immediate postnatal period than later in infancy because of the effect of neonatal and maternal oestrogen secretion.

There was no difference in endometrial thickness or uterine dimensions between girls at breast stage 4 or 5 who had menstruated and those who had not. 


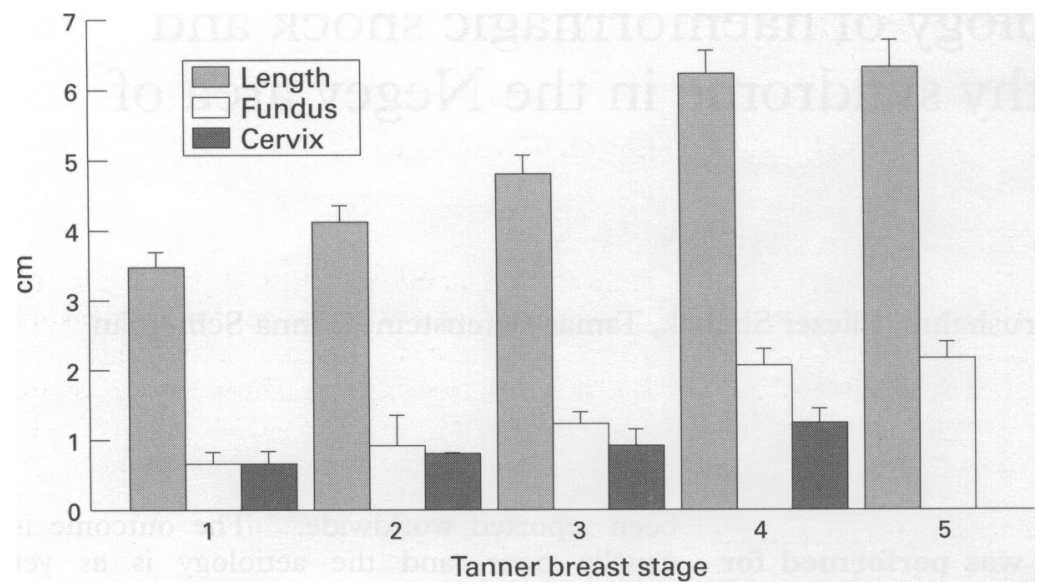

Figure 1 Graph showing mean (SE) uterine length and diameter at the fundus and cervix by breast stage.

\section{Discussion}

Ultrasound measurements of the uterus made by experienced operators are highly reproducible. It is technically easier to measure the uterus than the ovaries in children and linear ultrasound measurements are more reproducible than volume measurements. ${ }^{8}$

During childhood the uterus grew in length (fig 1), with diameters at fundus and cervix remaining approximately equal prepubertally. Somatic growth of ovarian volume during childhood was also observed in the same group of subjects. ${ }^{8}$ The increasing concentrations of circulating sex steroids during puberty resulted in growth and a change in shape. Growth in diameter at the fundus outstripped growth in diameter at the cervix and resulted in a pear shaped configuration. A similar change in uterine shape with puberty was documented by Griffin et al in a group of 153 girls. ${ }^{5}$

An increase in endometrial thickness was another marker of pubertal progress, although a thin endometrium was seen in some prepubertal girls, perhaps stimulated by the very low concentrations of oestrogen found in prepuberty. Measurement of endometrial thickness was no more helpful in predicting the time of onset of menstruation than pubertal rating. The mean endometrial thickness in girls who had menstruated but were not ovulating was thinner than that observed in older women during ovulatory cycles (a mean of $12.1 \mathrm{~mm}$

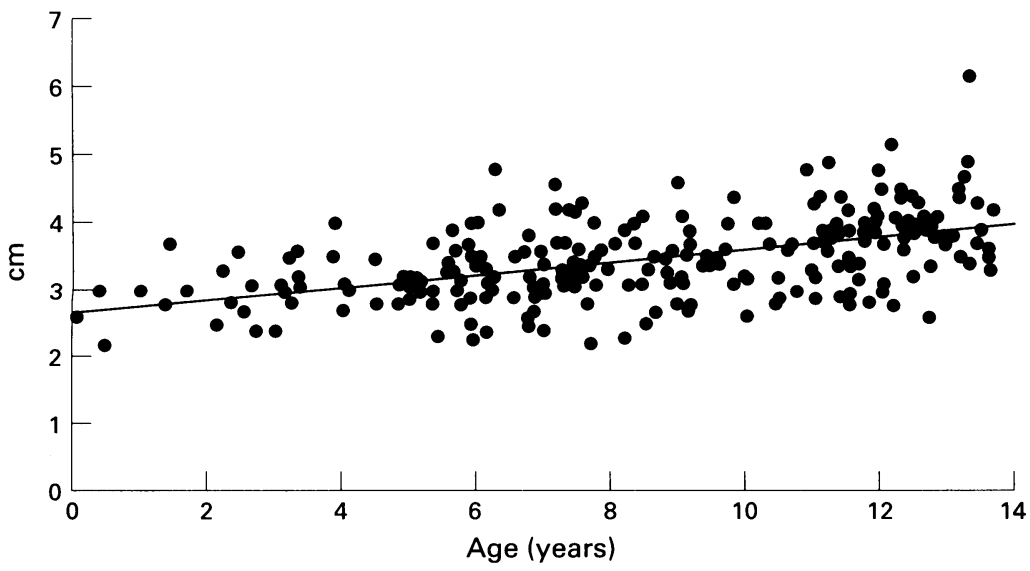

Figure 2 The measurements of uterine length at breast stage 1 plotted against age. The equation of the line was length $=0.093$ (age) $+2.67 ; r=0.50$.
Table 1 Age, number of patients, fundus: cervix ratio, and endometrial thickness divided by breast stage

\begin{tabular}{lllll}
\hline $\begin{array}{l}\text { Breast } \\
\text { stage }\end{array}$ & $\begin{array}{l}\text { Mean age } \\
\text { (years) }\end{array}$ & No & $\begin{array}{l}\text { Mean ratio of } \\
\text { fundus: cervix } \\
\text { (SE), range }\end{array}$ & $\begin{array}{l}\text { Endometrial } \\
\text { thickness (mm) } \\
\text { (SE), range }\end{array}$ \\
\hline 1 & 8.6 & 245 & $\begin{array}{l}0.95(0.02) \\
0.44-1.75\end{array}$ & $0.38(0.07)$ \\
& & & $0-4$ \\
2 & 11.3 & 112 & $\begin{array}{l}1.12(0.31) \\
1.02(0.15)\end{array}$ \\
3 & 11.8 & 57 & $\begin{array}{l}0.55-2.00 \\
1.26(0.04)\end{array}$ & $0-6$ \\
$2.79(0.28)$ \\
& & & $0.77-2.00$ & $0-8$ \\
4 & 13.3 & 34 & $\begin{array}{l}1.29(0.06) \\
1.0-1.83\end{array}$ & $\begin{array}{l}5.04(0.63) \\
2-17\end{array}$ \\
5 & 13.9 & 27 & $1.22(0.09)$ & $6.44(0.81)$ \\
& & & $0.75-2.13$ & $0-15$ \\
\hline
\end{tabular}

during the luteal phase in one study of normal women aged 21 to 25 years ${ }^{9}$ ).

There was considerable overlap in dimensions between pubertal stages. This study suggests that uterine shape was a better marker of pubertal development than uterine dimensions. The data are cross sectional and do not give information about the pattern of growth to be expected in an individual. Uterine growth may not follow along centile lines in the same manner as height. While the assessment of pubertal changes at ultrasound may be of importance in some conditions (for example in assessing girls with sexual precocity), the importance of relative uterine size at any pubertal stage on future development is not clear. Our group included individuals with heights above the 97th centile and below the 3 rd centile (unlike those in the study of Griffin et $a l^{5}$ ). There are no data on the relationship between height and uterine dimensions, but it may be that shorter girls have smaller uterine dimensions.

The onset of breast development at puberty is marked by uterine growth. A change in the shape of the uterus with growth in the diameter at the fundus overtaking growth at the cervix (adopting a pear shape) is a marker of puberty.

NAB was supported by the Special Trustees of the Middlesex Hospital, and PCH by Children Nationwide and Pharmacia.

We are grateful to the members of the Ultrasound Department at The Middlesex Hospital for performing the
scans, particularly Ms Anita Patel, Ms Claire Webber, Ms Jan scans, particularly Ms Anita Patel, Ms Claire Webt
Oliver, Ms Judy Adams, and Ms Sandra Mather.

Bergqvist A, Ferno $M$. Estrogen and progesterone receptors in endometriotic tissue and endometrium: comparison according to localization and recurrence. Fertil Steril according to

2 Lessey BA, Killam AP, Metzger DA, Haney AF, Greene GL, McCarty KS. Immunohistochemical analysis of human uterine estrogen and progesterone receptors throughout the menstrual cycle. $\mathcal{F}$ Clin Endocrinol Metab 1988;67:334 40.

3 Ivarsson SA, Nilsson KO, Persson PH. Ultrasonography of the pelvic organs in prepubertal and postpubertal girls. Arch Dis Child 1983;58:352-4.

4 Salardi S, Forsini L, Cacciari E, Bovicelli, Tassoni P, Regianni A. Pelvic ultrasonography in premenacheal girls: relation to puberty and sex hormone concentrations. Arch Dis Child 1985;60:120-5.

5 Griffin IJ, Cole TJ, Duncan KA, Hollman AS, Donaldson MDC. Pelvic ultrasound measurements in normal girls. Acta Paediatr 1995;84:536-43.

6 Tanner JM. Growth at adolescence. Oxford: Blackwell, 1962

Altman DG. Practical statistics for medical research. London: Chapman and Hall, 1991: 398-403.

8 Bridges NA, Cooke A, Healy MJR, Hindmarsh PC, Brook CGD. Standards for ovarian volume in childhood and CGD. Standards for ovarian volu

9. puberty. Fertil Steril 1993;60.456-60. changes in the female reproductive cycle. Br $\mathcal{F}$ Obstet Gynaecol 1994;101:229-33. 